\title{
Classification of artisanal Andalusian cheeses on physicochemical parameters applying multivariate statistical techniques
}

\author{
María Auxiliadora de la Haba Ruiz ${ }^{1}$. \\ Pilar Ruiz Pérez-Cacho ${ }^{1}$ - Rafaela Dios Palomares ${ }^{2}$. \\ Hortensia Galán-Soldevilla ${ }^{1}$
}

Received: 16 February 2015 / Revised: 5 June 2015 / Accepted: 15 June 2015 /

Published online: 7 July 2015

(C) INRA and Springer-Verlag France 2015

\begin{abstract}
In order to obtain a Protected Designation of Origin, it is necessary to characterize the food product. The objective of this work was to investigate whether there was a single Andalusian artisanal goat' milk cheese or several types, depending on the goat breed and/or the cheese-making process (milk heat treatment, rennet type or ripening time). One hundred and eight artisanal goat cheeses, representative of the whole area of Andalusia and widely distributed, have been physicochemically analyzed ( $\mathrm{pH}, \mathrm{TS}$, fat/TS, and $\mathrm{NaCl}$ ). Linear regression models were suitable for studying which factors had an independent influence on the physicochemical parameters of these cheeses, the breed and the ripening time being the most influential factors. A Kmeans cluster analysis with the principal component analysis (PCA) scores was made in order to find profiles which defined these cheeses. The first group was composed of Malagueña fresh cheeses made with pasteurized milk and microbial rennet and which had a higher $\mathrm{pH}$ (6.2) and lower values of TS (53.5), fat (26.1), fat/TS (49.2), and $\mathrm{NaCl}$ (1.5) than the second cheese group. The second profile was made up of MurcianoGranadina and multi-breed semihard and hard cheeses made with pasteurized or raw milk and animal or vegetable rennet and having lower $\mathrm{pH}$ values (5.4) than group 1 and higher TS (62.5), fat (34.4), fat/ TS (54.7), and $\mathrm{NaCl}$ (2.0) values than group 1. These results could support the Quesos de Málaga Producer's Association that is interested in applying for the Málaga fresh cheese quality certification (Protected Designation of Origin).
\end{abstract}

Hortensia Galán-Soldevilla

hgalan@uco.es

1 Departamento de Bromatología y Tecnología de los Alimentos, Universidad de Córdoba, Campus de Rabanales, 14070 Córdoba, Spain

2 Departamento Estadística, Econometría, Investigación Operativa, Organización de Empresas y Economía Aplicada, Universidad de Córdoba, Campus de Rabanales, 14070 Córdoba, Spain 
Keywords $\mathrm{PDO} \cdot$ Málaga fresh cheese · Goat's milk · Artisanal cheese

\section{Introduction}

Andalusia is the leading goat's milk producer in Spain and the second in the European Union after the Poitou-Charentes region in France (Castel et al. 2011). The milk is mainly used for artisanal cheese-making as Andalusia has an important cheese heritage. This region's goat-cheese production takes place mainly in small-scale factories using traditional methods with a milk production of below 25001 of milk per day. These traditional full-fat cheeses are made of either raw or pasteurized goat's milk from Andalusia's indigenous breeds (Malagueña, Murciano-Granadina, Florida, Payoya) or multi-breed herds. The cheeses have a natural rind and are cylindrical with different sizes. The cheeses are processed according to the traditional method (Navarro et al. 2009): the milk curdled in about $30 \mathrm{~min}$ at $31-33{ }^{\circ} \mathrm{C}$ habitually using kid rennet although vegetable or microbial (Mucor miehei) rennet may be used. The curd's grain sizes are like chickpeas for fresh cheeses and lentils for semihard and hard cheeses. The curd is transferred in a cloth to pierced plastic containers where it is pressed until most of the whey has been drained. After draining, the curd is treated in brine (15-18 ${ }^{\circ}$ Baume) in order for the salt to be uniformly distributed throughout it during a variable time, which depends on the size of the cheese and the temperature of the brine. The ripening takes place in chambers at a temperature of $10-12{ }^{\circ} \mathrm{C}$ with a relative humidity which ranges from 80 to $85 \%$ for 45 days (semihard) or longer (hard). Finally, the cheeses can be coated with spices or virgin olive oil. Thus, the characteristics of these cheeses are mainly influenced by the original milk's characteristics (indigenous breed and livestock feeding) and the cheese-making process (milk heat treatment, rennet type, or ripening time). For that reason, Andalusia has a large variety of excellent quality cheeses linked to their original terrain. Thus, Malaga artisanal cheesemakers are interested in applying for a quality certification for Malagueña fresh cheeses.

Nowadays, Spain has 27 Protected Designation of Origin (PDO) cheeses. Six of these certifications belong to goat's cheese (Camerano, Ibores, Majorero, Murcia, Murcia al Vino, and Palmero). None of these cheeses come from the Andalusian region. Although there are studies of goat cheese characteristics in Camerano cheese (Gonzalez-Fandos et al. 2000), in Ibores cheese (Mas et al. 2002), in Majorero cheese (Alvarez et al. 2007; Fresno and Alvarez 2012; Sanchez-Macias et al. 2010), in Murcia al Vino cheese (Tejada et al. 2008), in Palmero cheese (Fresno et al. 2011), and in Tenerife cheese (Peláez Puerto et al. 2004), reports on traditional Andalusian cheeses have been sparse or not updating (Fernández-Salguero and Gómez Díaz 1997) or examining their nutritional aspects (Moreno-Rojas et al. 2010). To the best of our knowledge, no recent studies have reported the effect of the breed, ripening time, rennet type, or heat treatment on the physicochemical properties of Andalusian artisanal goat's milk cheese.

In order to obtain a quality certification, it is necessary to characterize the food product and to evaluate whether there are any differences between similar cheeses made within the region. The aim of this work was to study if there was a single Andalusian 
artisanal goat's cheese or several types, influenced by the goat breed and/or the cheese making process (milk heat treatment, rennet type or ripening time) based on its physicochemical parameters using multivariate techniques.

\section{Material and methods}

\subsection{Samples}

One hundred and eight cheeses were obtained from 40 local producers representing the entire Andalusia artisan cheese-making industry (Galán-Soldevilla and Ruiz PérezCacho 2010). Origin and principal characteristics of the cheeses analyzed (ripening time, heat treatment, breed, and type of rennet) are shown in Table 1. These cheeses are made mainly with pasteurized goat's milk from Malagueña or Murciano-Granadina breeds using animal rennet and most of the factories are located in Malaga.

\subsection{Determination of the chemical components and $\mathrm{pH}$}

$\mathrm{pH}$, total solids (TS, expressed as $\mathrm{g} / 100 \mathrm{~g}$ cheese), fat (g/100 g cheese), fat/TS ( $\mathrm{g} / 100 \mathrm{~g}$ $\mathrm{TS}$ ), and sodium chloride (g/100 g cheese) were analyzed. Fat content was measured according to the FIL-IDF methods (ISO/IDF 2008). TS content was determined following the official method (AOAC 1999). The $\mathrm{pH}$ was measured with a $\mathrm{pH}$ meter (pHmetro HANNA FHT-803) with a pH electrode. The sodium chloride content was analyzed using a back titration with potassium thiocyanate to determine the

Table 1 Description of the general characteristics of the cheese samples studied

\begin{tabular}{|c|c|}
\hline Origin & Description \\
\hline Cádiz & $\begin{array}{l}\text { Fresh/semihard/hard cheese, pasteurized milk, Payoya breed, animal rennet } \\
\text { Fresh/semihard and hard cheese, pasteurized milk, multi-breed, animal rennet }\end{array}$ \\
\hline Córdoba & $\begin{array}{l}\text { Fresh/hard cheese, pasteurized/raw milk, Malagueña breed, animal rennet } \\
\text { Hard cheese, pasteurized/raw milk, Murciano-Granadina breed, vegetable rennet } \\
\text { Semihard/hard cheese, pasteurized milk, multi-breed, vegetable rennet }\end{array}$ \\
\hline Granada & Fresh/semihard/hard cheese, pasteurized/raw milk, Murciano-Granadina breed, animal rennet \\
\hline Jaén & $\begin{array}{l}\text { Semihard cheese, pasteurized milk, Murciano-Granadina breed, vegetable rennet } \\
\text { Fresh/semihard/hard cheese, pasteurized milk, multi-breed, animal rennet }\end{array}$ \\
\hline Huelva & $\begin{array}{l}\text { Semihard/hard cheese, pasteurized milk, Malagueña breed, animal rennet } \\
\text { Hard cheese, pasteurized/raw milk, multi-breed, animal/vegetable rennet }\end{array}$ \\
\hline Malaga & $\begin{array}{l}\text { Fresh/semihard/hard cheese, pasteurized milk, Malagueña breed, animal rennet } \\
\text { Fresh cheese, pasteurized milk, Malagueña breed, microbial rennet } \\
\text { Fresh/semihard/hard cheese, pasteurized milk, Murciano-Granadina breed, animal rennet } \\
\text { Fresh/semihard/hard cheese, pasteurized/raw milk, multi-breed, animal rennet } \\
\text { Fresh/semihard/hard cheese, pasteurized/raw milk, multi-breed, vegetable rennet }\end{array}$ \\
\hline Sevilla & $\begin{array}{l}\text { Fresh/semihard and hard cheese, pasteurized/raw milk, Florida breed, microbial rennet } \\
\text { Hard cheese, raw milk, Murciano-Granadina/multi-breed, animal rennet }\end{array}$ \\
\hline
\end{tabular}


concentration of chloride ions in a solution (Volhard method, AOAC 1999). All determinations were made in duplicate.

\subsection{Statistical analysis}

The data reported in all the tables are averages of duplicate observations. Descriptive statistics and Pearson correlations were applied to the observed variables. Twenty twoway analyses of variance (ANOVA) were performed considering each of the five physicochemical parameters as dependent variable with each two of the four factors in accordance with the following designs: (breed $\times$ ripening time), (breed $\times$ heat treatment), (rennet $\times$ ripening time) and (rennet $\times$ heat treatment) in order to analyze not only the factor effects but also the interactions between factors. The (breed $\times$ rennet) and (ripening time $\times$ heat treatment) ANOVAs were not performed because we had no data from all the experimental points. In the first case, there were no Malagueña cheeses made with vegetable rennet and in the second, there were no fresh or semihard cheeses made from raw milk. Linear regression models were developed to explain and predict cheese characteristics. It was interesting to determine if the factors were independent prognostic of the characteristics. If this was so, we would be able to discriminate different cheeses by their characteristics, and we could also form groups of cheeses which have common and specified characteristics. In order to define these groups, the following additional multivariate techniques were applied: (1) factor analysis using principal components as a factor extraction method and (2) K-means cluster analysis. All the statistics were carried out with SPSS 17.A.

\section{Results and discussion}

\subsection{Physicochemical characterization}

Most of the cheese were made from Malagueña and Murciano-Granadina or multibreed herd milk. Very few cheeses are made from either Payoya or Florida breed milk. For statistical purposes, it was decided to include these two breeds in the multi-breed cheese group.

Pearson correlation coefficients for the relationships between the physicochemical variables $(\mathrm{pH}, \mathrm{TS}$, fat, fat/TS and $\mathrm{NaCl})$ are presented in Table $2 . \mathrm{pH}$ was negatively correlated $(p<0.01)$ with TS $(r=-0.528)$, fat $(r=-0.547)$, fat/TS $(r=-0.181)$ and $\mathrm{NaCl}$

Table 2 Pearson correlation coefficients for the physicochemical characteristics of cheeses

\begin{tabular}{|c|c|c|c|c|}
\hline & TS & Fat & Fat/TS & $\mathrm{NaCl}$ \\
\hline $\mathrm{pH}$ & $-0.528 * *$ & $-0.547^{* *}$ & $-0.181 * *$ & $-0.218^{* *}$ \\
\hline $\mathrm{TS}$ & & $0.776^{* *}$ & -0.052 & $0.545^{* *}$ \\
\hline Fat & & & $0.534 * *$ & $0.449 * *$ \\
\hline Fat/TS & & & & 0.005 \\
\hline
\end{tabular}

$* * p<0.01$ 
$(r=-0.218)$. Thus, the cheeses with higher values of $\mathrm{pH}$ had lower values of TS, fat, fat/ $\mathrm{TS}$ and $\mathrm{NaCl}$, with the relationship between the $\mathrm{pH}$ with the TS and the fat being higher than that with the $\mathrm{NaCl}$. TS was positively correlated $(p<0.01)$ with fat $(r=0.776)$ and $\mathrm{NaCl}(r=0.545)$ content. Therefore, the cheeses with higher values of TS had higher values of fat and $\mathrm{NaCl}$. The relationship between the TS and the fat was higher rather than that between the TS and the $\mathrm{NaCl}$. Fat was positively correlated $(p<0.01)$ with fat/TS $(r=0.534)$ and with the $\mathrm{NaCl}$ content $(r=0.449)$. The highest relationship was between the fat and the fat/TS.

Table 3 presents the results of the descriptive analysis (mean and typical deviation) and of the analysis of variance ( $F$ and $p$ value). The columns correspond to the analytical parameters determined $(\mathrm{pH}, \mathrm{TS}$, fat, fat/TS, and $\mathrm{NaCl})$ and the rows to the factors studied

Table 3 Descriptive measures (means values and standard deviation) and analysis of variance of physicochemical parameters ( $F$ and $P$ values)

\begin{tabular}{|c|c|c|c|c|c|c|}
\hline Effect & & $\mathrm{pH}$ & $\begin{array}{l}\mathrm{TS} \\
(\mathrm{g} / 100 \mathrm{~g} \\
\text { cheese) }\end{array}$ & $\begin{array}{l}\text { Fat } \\
\text { (g/100 g } \\
\text { cheese) }\end{array}$ & $\begin{array}{l}\text { Fat/TS } \\
\text { (g/100 g } \\
\text { TS) }\end{array}$ & $\begin{array}{l}\mathrm{NaCl} \\
(\mathrm{g} / 100 \mathrm{~g} \\
\text { cheese) }\end{array}$ \\
\hline \multirow[t]{5}{*}{ Breed } & Murciano-Granadina & $5.3 \pm 0.5^{\mathrm{a}}$ & $62.0 \pm 6.0$ & $34.7 \pm 3.6^{\mathrm{a}}$ & $56.0 \pm 3.3^{\mathrm{a}}$ & $2.0 \pm 0.7$ \\
\hline & Malagueña & $5.8 \pm 0.6^{\mathrm{b}}$ & $59.1 \pm 8.0$ & $29.7 \pm 4.7^{\mathrm{b}}$ & $50.4 \pm 5.1^{\mathrm{b}}$ & $1.8 \pm 0.5$ \\
\hline & Multi-breed & $5.6 \pm 0.5^{\mathrm{c}}$ & $60.4 \pm 7.7$ & $32.7 \pm 4.7^{\mathrm{c}}$ & $53.7 \pm 4.0^{\mathrm{c}}$ & $1.9 \pm 0.6$ \\
\hline & $F$ & 11.23 & & 15.35 & 22.53 & \\
\hline & $p$ & 0.000 & $\mathrm{~ns}$ & 0.000 & 0.000 & $\mathrm{~ns}$ \\
\hline \multirow[t]{5}{*}{ Rennet } & Animal & $5.6 \pm 0.5^{\mathrm{a}}$ & $61.2 \pm 7.6^{\mathrm{a}}$ & $32.7 \pm 5.0^{\mathrm{a}}$ & $53.2 \pm 4.5$ & $2.0 \pm 0.6^{\mathrm{a}}$ \\
\hline & Vegetable & $5.3 \pm 0.5^{\mathrm{b}}$ & $60.4 \pm 6.3^{\mathrm{a}}$ & $32.8 \pm 3.4^{\mathrm{a}}$ & $54.6 \pm 5.1$ & $1.6 \pm 0.6^{\mathrm{b}}$ \\
\hline & Microbial & $6.1 \pm 0.6^{\mathrm{c}}$ & $52.7 \pm 7.2^{\mathrm{b}}$ & $28.0 \pm 4.8^{\mathrm{b}}$ & $53.0 \pm 3.3$ & $1.8 \pm 0.6^{\mathrm{ab}}$ \\
\hline & $F$ & 14.27 & 9.66 & 7.56 & & 4.40 \\
\hline & $p$ & 0.000 & 0.000 & 0.001 & ns & 0.000 \\
\hline \multirow[t]{5}{*}{ Ripening time } & Fresh & $6.0 \pm 0.6^{\mathrm{a}}$ & $49.6 \pm 5.2^{\mathrm{a}}$ & $25.7 \pm 3.4^{\mathrm{a}}$ & $51.7 \pm 4.2^{\mathrm{a}}$ & $1.3 \pm 0.4^{\mathrm{a}}$ \\
\hline & Semihard & $5.5 \pm 0.3^{\mathrm{b}}$ & $60.3 \pm 4.5^{\mathrm{b}}$ & $32.3 \pm 3.4^{\mathrm{b}}$ & $53.7 \pm 5.0^{\mathrm{b}}$ & $2.0 \pm 0.5^{\mathrm{b}}$ \\
\hline & Hard & $5.4 \pm 0.3^{\mathrm{c}}$ & $64.1 \pm 6.2^{\mathrm{c}}$ & $34.8 \pm 3.7^{\mathrm{c}}$ & $53.8 \pm 4.3^{\mathrm{b}}$ & $2.0 \pm 0.6^{\mathrm{b}}$ \\
\hline & $F$ & 103.39 & 96.24 & 91.91 & 3.30 & 28.91 \\
\hline & $p$ & 0.000 & 0.000 & 0.000 & 0.039 & 0.000 \\
\hline \multirow[t]{4}{*}{ Heat treatment } & Pasteurized & $5.6 \pm 0.6^{\mathrm{a}}$ & $59.8 \pm 7.9^{\mathrm{a}}$ & $31.8 \pm 5.0^{\mathrm{a}}$ & $53.2 \pm 4.6$ & $1.9 \pm 0.6$ \\
\hline & Raw & $5.4 \pm 0.2^{\mathrm{b}}$ & $62.7 \pm 6.1^{\mathrm{b}}$ & $34.7 \pm 3.3^{\mathrm{b}}$ & $54.2 \pm 4.4$ & $2.0 \pm 0.6$ \\
\hline & $F$ & 4.54 & 5.31 & 12.68 & & \\
\hline & $p$ & 0.034 & 0.022 & 0.000 & $\mathrm{~ns}$ & $\mathrm{~ns}$ \\
\hline \multirow[t]{2}{*}{ Breed $\times$ ripening time } & $F$ & & & & & \\
\hline & $p$ & 0.000 & 0.027 & 0.020 & 0.007 & $\mathrm{~ns}$ \\
\hline \multirow[t]{2}{*}{ Breed $\times$ heat treatment } & $F$ & & & & & \\
\hline & $p$ & 0.049 & 0.015 & 0.040 & 0.000 & $\mathrm{~ns}$ \\
\hline \multirow[t]{2}{*}{ Rennet $\times$ ripening time } & $F$ & & & & & \\
\hline & $p$ & ns & ns & $\mathrm{ns}$ & $\mathrm{ns}$ & $\mathrm{ns}$ \\
\hline \multirow[t]{2}{*}{ Rennet $\times$ heat treatment } & $F$ & & & & & \\
\hline & $p$ & ns & $\mathrm{ns}$ & $\mathrm{ns}$ & $\mathrm{ns}$ & $\mathrm{ns}$ \\
\hline
\end{tabular}


(breed, ripening time, rennet, and heat treatment) with their corresponding levels. Further, the Tukey comparison of means test, which permits one to find out between which levels the difference lies, was performed. Finally, the results of the analysis of variance ( $F$ and $p$ value) of the interactions studied (breed $\times$ ripening time, breed $\times$ heat treatment, rennet $\times$ ripening time and rennet $\times$ heat treatment) are shown. The effect of breed was only significant for $\mathrm{pH}$, fat and fat/TS $(p<0.001)$, and there were (breed $\times$ ripening time) and (breed $\times$ heat treatment) interaction effects for all parameters studied except for the $\mathrm{CINa}$ content ( $p<0.05$, Table 3). Murciano-Granadina cheeses had a lower $\mathrm{pH}$ (5.3) and higher fat (34.7) and fat/TS contents (56.0) than Malagueña cheeses (5.8, 29.7, and 50.4, respectively; Table 3). Fat content is the milk component most quantitatively and qualitatively variable and depend on lactation stage, season, breed, feeding, and genotype (Raynal-Ljutovac et al. 2008). Thus, there is substantial evidence to show that the polymorphism of the goat $\alpha 1$-casein (CSN1S1) gene has a major effect on milk protein, casein, and fat content. According to different authors (Barbieri et al. 1995; Mahe et al. 1994), high content alleles are associated with higher protein, fat, and casein contents. Furthermore, higher average values of CSN1S1 content in milk from MurcianoGranadina goats were found than in Malagueña goats (Caravaca et al. 2008). The fat/ TS content values found in our study for cheeses made from Murciano-Granadina goats' milk were similar to those reported for Murcia al Vino cheese (Tejada et al. 2008) but higher than in cheeses made from milk from different Spanish breeds such as Palmera or Majorero (Fresno and Alvarez 2012; Sanchez-Macias et al. 2010).

The $\mathrm{pH}$, fat content, TS value and sodium chloride level were affected by the type of rennet used $(p<0.001)$. Thus, the microbial coagulant showed the highest average $\mathrm{pH}$ data (6.1) and the lowest fat (28) and TS (52.7) content. However, there were no differences in TS and fat contents between the animal and vegetable coagulants $(p>0.05)$ as has been observed in Murcia al Vino cheese (Tejada et al. 2008) and in different ewe's milk cheese varieties (Galan et al. 2008, 2012; Tejada and FernandezSalguero 2003). Other studies on the influence of diet and rennet on the composition of goat's milk and cheese reported that diet exerted a greater influence on the chemical composition of the cheeses than the rennet used in their production (Fresno et al. 2011).

As was expected, ripening affected all physicochemical parameters $(p<0.001)$. The final average $\mathrm{pH}$ data observed in our study showed values of 6.0 for fresh, 5.5 for semihard and 5.4 for hard cheeses. These $\mathrm{pH}$ fluctuations were also observed by other researchers, who reported a significant decrease in $\mathrm{pH}$ in the first 15 days of ripening that continued, although it was less pronounced, until the 30th day of ripening and then it showed a slight increase in 60- and 90-day-old cheeses (Alvarez et al. 2007). The pH values obtained in our study were close to the range of values observed by different authors for other goat's milk cheeses manufactured in Andalusia (Fernández-Salguero and Gómez Díaz 1997) and in other regions of Spain (Fresno and Alvarez 2012; Fresno et al. 2011; Gonzalez-Fandos et al. 2000; Peláez Puerto et al. 2004; Tejada et al. 2008). The results obtained for fat and TS contents showed a tendency for their values to increase over the ripening period $(p<0.05)$. The TS values were similar to those published for other Spanish goat's milk cheeses (Mas et al. 2002; Tejada et al. 2008). Their fat content was in the same range as that reported by other authors (FernándezSalguero and Gómez Díaz 1997; Peláez Puerto et al. 2004). The fat/TS content changed significantly from fresh (51.7) to semihard (53.7) cheeses and then it remained constant until the end of ripening (53.8 for hard cheeses), as was observed by other authors 
(Fresno and Alvarez 2012). On the contrary, some other authors did not perceive any changes over the whole period of ripening (Tejada et al. 2008). The fat/TS content values found in our study were similar to those reported for Murcia al Vino cheese (Tejada et al. 2008) but higher than those in cheeses made in the Canary Islands (Fresno and Alvarez 2012; Peláez Puerto et al. 2004; Sanchez-Macias et al. 2010). Finally, the $\mathrm{NaCl}$ levels (1.3 for fresh and 2.0 for semihard and hard cheeses, respectively) are within the range of other Andalusian cheeses (Fernández-Salguero and Gómez Díaz 1997 ) and other Spanish goat's milk cheeses (Mas et al. 2002; Tejada et al. 2008).

The effect of heat treatment was significant for the $\mathrm{pH}$, TS and fat content $(p<0.05)$. Thus, cheeses made from raw milk showed lower $\mathrm{pH}$ values (5.4), a higher TS (62.7), and fat content (34.7) than the ones made from pasteurized milk ( $\mathrm{pH}$ 5.6; TS 59; fat content 31.8). Batzos cheeses made from raw goat's milk had a lower $\mathrm{pH}$ and lower moisture values than cheeses made from pasteurized milk (Psoni et al. 2006).

Finally, there were (breed $\times$ ripening time) and (breed $\times$ heat treatment) interaction effects for all parameters studied except for the CINa content $(p<0.05$, Table 3$)$ and the (rennet $\times$ ripening time) and the (rennet $\times$ heat treatment) interactions effects were not significant.

\subsection{Linear regression models}

As many factors could influence the physicochemical characteristics of Andalusian cheeses (breed, rennet, ripening time and heat treatment), a linear regression model for each characteristic was applied in order to estimate which factor had an independent influence on these analytical parameters. Table 4 shows the results of the five models estimated. In all the models, one category in each factor was omitted, so that the estimated coefficient reflects the effect due to the corresponding category with respect to the omitted one. The omitted categories were Murciano-Granadina (breed), microbial (rennet), fresh cheese (ripening time) and pasteurization (heat treatment). To

Table 4 Linear regression models on the physicochemical characteristics of cheeses

\begin{tabular}{llllll}
\hline & $\mathrm{pH}$ & $\begin{array}{l}\mathrm{TS} \\
(\mathrm{g} / 100 \mathrm{~g} \text { cheese })\end{array}$ & $\begin{array}{l}\text { Fat } \\
(\mathrm{g} / 100 \mathrm{~g} \text { cheese })\end{array}$ & $\begin{array}{l}\text { Fat/TS } \\
(\mathrm{g} / 100 \mathrm{~g} \mathrm{TS})\end{array}$ & $\begin{array}{l}\mathrm{NaCl} \\
(\mathrm{g} / 100 \mathrm{~g} \text { cheese })\end{array}$ \\
\hline Constant & $6.268^{* * *}$ & $48.964^{* * *}$ & $27.329^{* * *}$ & $55.376^{* * *}$ & $1.745^{* * *}$ \\
Malagueñ & $0.217^{* *}$ & -0.232 & $-3.495^{* * *}$ & $-5.237^{* * *}$ & -0.197 \\
Multi-breed & $0.155^{*}$ & -0.644 & $-1.331^{*}$ & $-2.040^{* *}$ & -0.170 \\
Animal & -0.055 & 1.676 & 0.835 & -0.545 & $-0.325^{*}$ \\
Vegetable & -0.163 & -1.246 & -1.087 & -0.445 & $-0.800^{* * *}$ \\
Semihard & $-0.795^{* * *}$ & $10.538^{* * *}$ & $6.024 * * *$ & 1.138 & $0.727^{* * *}$ \\
Hard & $-0.993^{* * *}$ & $15.709^{* * *}$ & $8.637 * * *$ & 0.818 & $0.943^{* * *}$ \\
Raw & 0.115 & $-2.742^{*}$ & -0.343 & 0.735 & -0.157 \\
R squared & 0.531 & 0.509 & 0.527 & 0.482 & 0.433 \\
$F$ & 33.60 & 30.83 & 33.05 & 6.76 & 14.148 \\
$p$ & 0.000 & 0.000 & 0.000 & 0.000 & 0.000 \\
\hline
\end{tabular}

${ }^{*} p<0.05 ; * * p<0.01 ; * * * p<0.001$ 
explain the $\mathrm{pH}$, the breed and the ripening time are independent prognostic factors, the coefficient of determination being $R^{2}=0.531, F=33.6$ and $p<0.0001$. Regarding the TS, the ripening time and the heat treatment are independent prognostic factors, and $R^{2}=0.509, F=30.8$ and $p<0.0001$. Concerning the fat content, the breed and ripening time are independent prognostic factors, as studied for the $\mathrm{pH}$, and $R^{2}=0.527, F=33.05$ and $p<0.0001$. In terms of fat/TS, the breed was the only independent prognostic factor, this being the $R^{2}=0.482, F=6.76$ and $p<0.0001$. Regarding the salt $(\mathrm{NaCl})$ content, the rennet and ripening time were independent prognostic factors and were $R^{2}=0.433, F=14.1$ and $p<0.0001$. Therefore, the breed and the ripening time are the factors with most influence on the physicochemical parameters of these cheeses. The breed had an independent effect on $\mathrm{pH}$, fat content and $\mathrm{TS} /$ fat and the ripening time on the $\mathrm{pH}, \mathrm{TS}$, fat content and $\mathrm{NaCl}$. The rennet did not have any significant effect on any of the parameters studied since salt is a technological variable controlled by the artisans and the heat treatment only affects the TS content of the cheeses. Thus, although the results of the ANOVA (Table 3) indicate that all the factors have a significant influence on the analytical parameters studied, based on this model, breed and ripening time were the most significant ones.

\subsection{Multivariate analysis: principal component analysis and K-means cluster analysis}

A multivariate factorial analysis was applied to the physicochemical characteristics of the cheeses in order to identify possible relationships and reduce the dimension of the space that explains these parameters ( $\mathrm{pH}, \mathrm{TS}$, fat, TS/fat and sodium chloride). A two factor model that accounts for $73.4 \%$ of total variance was selected based on eigenvalues and on the contribution of the physicochemical characteristics to the relevant axes.

Figure 1 shows the plotting of physicochemical parameters on the plane defined by the two components and the score plot for the cheese samples. The first dimension

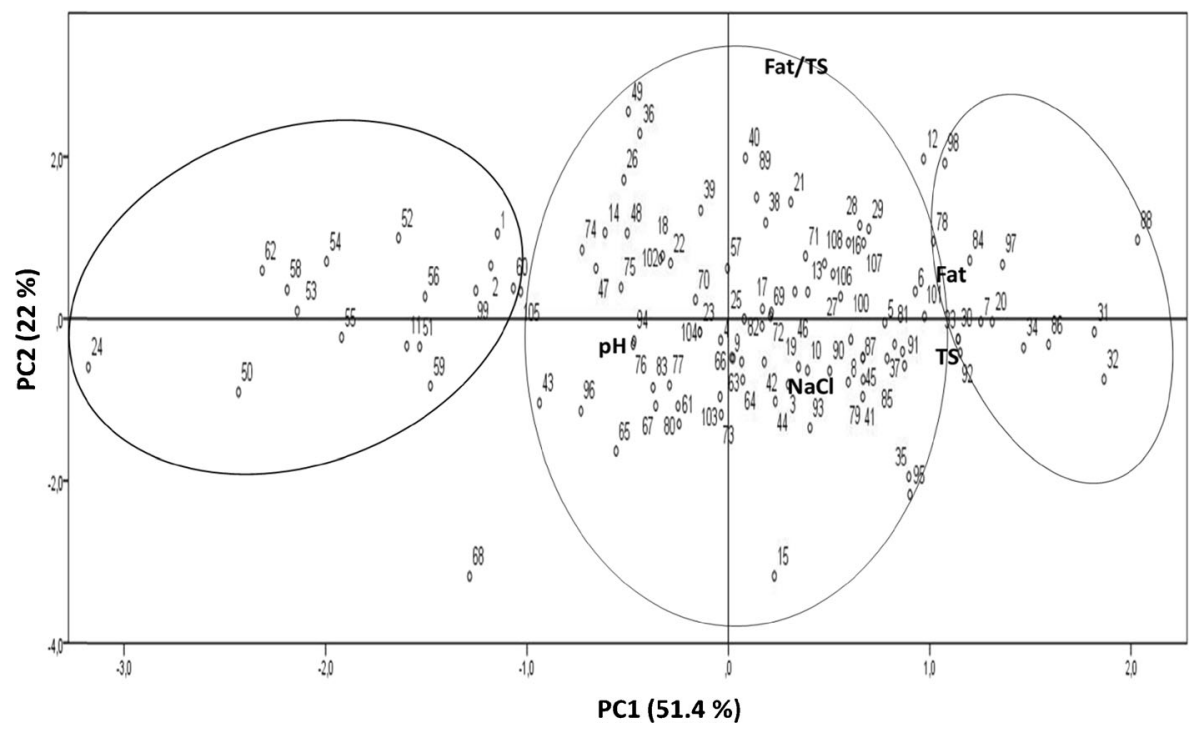

Fig. 1 PCA score plot of Andalusian goat's cheeses using the first two factors (PC1 vs. PC2) obtained from the PCA 
$(51.4 \%)$ selects the fat, $\mathrm{TS}$ and the $\mathrm{pH}$ and separates those cheeses with a higher $\mathrm{pH}$ and lower TS and fat content from cheeses with a lower $\mathrm{pH}$ and a higher TS and fat content. The second dimension (22\%) is mainly defined by the fat/TS. From the results obtained, it was observed that PC1 separates cheeses into three groups which are not clearly differentiated: the first group is composed of fresh cheeses made with milk from the Malagueña breed or multi-breed milk $(1,2,11,24,50,51,52,53,54,55,56,58,59,60,62$ and 99) with a lower fat content and a higher $\mathrm{pH}$, the second group is formed by hard cheeses made with milk from the Murciano-Granadina breed or multibreed milk (7, 20, 30, 31, 32, 33, 34, 84, 86, 88, 92, 97 and 98) with a higher fat content and a lower $\mathrm{pH}$, and a third group is composed of semihard and hard cheeses processed with milk regardless of the goat breed. The main reason was that the $\mathrm{pH}$ was negatively correlated with the fat content (Table 2), and the cheeses made from the Malagueña breed milk had a higher $\mathrm{pH}$ and a lower fat content, while the cheeses from the Murciano-Granadina breed milk showed lower values of $\mathrm{pH}$ and a higher fat content (Table 3). In addition, the breed and the ripening time are independent prognostic factors for the $\mathrm{pH}$ and the fat content. The PC2 divides the third group into two subgroups according to their fat/TS content (breed is the only independent prognostic factor for this parameter): the top of the plane mostly assembles the cheeses made from the Murciano-Granadina breed and/or multi-breed milk and the bottom plane groups cheeses made from the Malagueña breed and/or multi-breed milk. A K-means cluster analysis with the principal component analysis (PCA) scores was made in order to find profiles which defined these cheeses.

The cluster analysis result shows two differentiated groups with 26 and 82 cheeses in each one, respectively (Table 5). The average values between the two created groups are significantly different $(p<0.001)$ for all physicochemical parameters. The cheeses belonging to group 1 have a higher mean value of $\mathrm{pH}$ and a lower mean value of TS, fat, fat/TS and sodium chloride than the cheeses belonging to group 2. In addition, all Murciano-Granadina breed milk cheeses belong to group 2, while the cheeses from Malagueña breed milk are equally distributed in both groups. Regarding the ripening time, the fresh cheeses mainly belong to group 1, while the semihard and hard cheeses predominate in group 2. In terms of rennet, the microbial rennet cheeses stand out in group 1 and animal and vegetable rennet cheeses in group 2. As for the heat treatment, the raw milk cheeses belong primarily to group 2. Consequently, two cheese profiles differentiated according to their characteristics can be established. The first profile is defined by Malagueña fresh cheeses made with pasteurized milk and microbial rennet and has a higher $\mathrm{pH}(6.2)$ and lower values of TS (53.5), fat (26.1), fat/TS (49.2), and $\mathrm{NaCl}$ (1.5) than the second cheese profile. The second profile is composed of Murciano-Granadina and multi-breed semihard and hard cheeses made with pasteurized or raw milk and animal or vegetable rennet and with lower $\mathrm{pH}$ values (5.4) than those of group 1 and higher TS (62.5), fat (34.4), fat/ TS (54.7), and $\mathrm{NaCl}$ (2.0) values than group 1. These results could support the Quesos de Málaga Producer's Association that is interested in applying for the Málaga fresh cheese quality certification (Protected Designation of Origin). 
Table 5 K-means cluster analysis on the physicochemical characteristics of cheeses

\begin{tabular}{|c|c|c|c|}
\hline Parameter & Mean standard deviation & Cluster number & Number of cheeses \\
\hline \multirow[t]{2}{*}{$\mathrm{pH}$} & $6.2 \pm 0.6$ & 1 & 26 \\
\hline & $5.4 \pm 0.3$ & 2 & 82 \\
\hline \multirow[t]{2}{*}{ TS (g/100 g cheese) } & $53.5 \pm 8.2$ & 1 & 26 \\
\hline & $62.5 \pm 6.1$ & 2 & 82 \\
\hline \multirow[t]{2}{*}{ Fat (g/100 g cheese) } & $26.1 \pm 3.1$ & 1 & 26 \\
\hline & $34.4 \pm 3.4$ & 2 & 82 \\
\hline \multirow[t]{2}{*}{ Fat/TS (g/100 g TS) } & $49.2 \pm 4.4$ & 1 & 26 \\
\hline & $54.7 \pm 3.7$ & 2 & 82 \\
\hline \multirow[t]{2}{*}{$\mathrm{NaCl}(\mathrm{g} / 100 \mathrm{~g}$ cheese $)$} & $1.5 \pm 0.5$ & 1 & 26 \\
\hline & $2.0 \pm 0.5$ & 2 & 82 \\
\hline \multicolumn{4}{|l|}{ Effect } \\
\hline \multirow[t]{6}{*}{ Breed } & Murciano-Granadina & 1 & 0 \\
\hline & & 2 & 23 \\
\hline & Malagueña & 1 & 13 \\
\hline & & 2 & 14 \\
\hline & Multi-breed & 1 & 12 \\
\hline & & 2 & 46 \\
\hline \multirow[t]{6}{*}{ Rennet } & Animal & 1 & 17 \\
\hline & & 2 & 64 \\
\hline & Vegetable & 1 & 2 \\
\hline & & 2 & 17 \\
\hline & Microbial & 1 & 6 \\
\hline & & 2 & 2 \\
\hline \multirow[t]{6}{*}{ Ripening time } & Fresh & 1 & 17 \\
\hline & & 2 & 2 \\
\hline & Semihard & 1 & 5 \\
\hline & & 2 & 28 \\
\hline & Hard & 1 & 3 \\
\hline & & 2 & 53 \\
\hline \multirow[t]{4}{*}{ Heat treatment } & Pasteurized & 1 & 24 \\
\hline & & 2 & 62 \\
\hline & Raw & 1 & 2 \\
\hline & & 2 & 20 \\
\hline
\end{tabular}

$p<0.001$

\section{Conclusions}

Results showed that the breed and the ripening time are the most influential factors on the physicochemical parameters of these cheeses. The breed had an independent influence on $\mathrm{pH}$, fat content and $\mathrm{TS} /$ fat and the ripening time on $\mathrm{pH}$, TS, fat content and $\mathrm{NaCl}$. Two groups of different Andalusian artisanal goat's milk cheeses were 
established using multivariate techniques: one defined by fresh cheese made with milk from the Malagueña breed and the other formed by semihard and hard cheeses elaborated with milk from the Murciano-Granadina and/or multi-breed goats. Multivariate techniques could be applied to different contexts, with other products and in different areas, so that it would help those researchers interested in cooperating with local producers to establish profiles of products with homogeneous characteristics.

Acknowledgments We express our gratitude to "Grupo de Desarrollo Rural Valle del Guadalhorce", Málaga (Spain) for providing funds to conduct this research project. We should also like to thank the local producers for providing the samples.

\section{References}

Alvarez S, Fresno M, Mendez P, Castro N, Fernandez JR, Sampelayo MRS (2007) Alternatives for improving physical, chemical, and sensory characteristics of goat cheeses: the use of arid-land forages in the diet. J Dairy Sci 90:2181-2188

AOAC (1999) Official methods of analysis, 16th edn. Association of Official Analytical Chemists, Washington, DC

Barbieri ME, Manfredi E, Elsen JM, Ricordeau G, Bouillon J, Grosclaude F, Mahe MF, Bibe B (1995) Effect of the alpha(S1)-casein locus on dairy performances and genetic-parameters of Alpine goats. Genet Sel Evol 27:437-450

Caravaca F, Amills M, Jordana J, Angiolillo A, Agueera P, Aranda C, Menendez-Buxadera A, Sanchez A, Carrizosa J, Urrutia B, Sanchez A, Manuel Serradilla J (2008) Effect of alpha(s1)-casein (CSN1S1) genotype on milk CSN1S1 content in Malaguena and Murciano-Granadina goats. J Dairy Res 75:481484

Castel JM, Mena Y, Ruiz FA, Camunez-Ruiz J, Sanchez-Rodriguez M (2011) Changes occurring in dairy goat production systems in less favoured areas of Spain. Small Rumin Res 96:83-92

Fernández-Salguero J, Gómez Díaz R (1997) Estudio de los quesos tradicionales de Andalucía. In. Publicaciones de la Universidad de Córdoba y Obra Social y Cultural Cajasur, Córdoba

Fresno M, Alvarez S (2012) Chemical, textural and sensorial changes during the ripening of Majorero goat cheese. Int J Dairy Technol 65:393-400

Fresno M, Alvarez S, Rodriguez E, Diaz C, Darias J, Martin J (2011) Influence of diet and rennet on the composition of goats' milk and cheese. J Dairy Res 78:250-256

Galán-Soldevilla H, Ruiz Pérez-Cacho P (2010) Andalusian artisan cheese survey. Universidad de Córdoba, Córdoba (Spain). Private report to Andalusian artisan cheese-making factories

Galan E, Cabezas L, Fernandez-Salguero J (2012) Proteolysis, microbiology, and sensory properties of ewes' milk cheese produced with plant coagulant from cardoon Cynara cardunculus, calf rennet or a mixture thereof. Int Dairy J 25:92-96

Galan E, Prados F, Pino A, Tejada L, Fernandez-Saguero J (2008) Influence of different amounts of vegetable coagulant from cardoon Cynara cardunculus and calf rennet on the proteolysis and sensory characteristics of cheeses made with sheep milk. Int Dairy J 18:93-98

Gonzalez-Fandos E, Sanz S, Olarte C (2000) Microbiological, physicochemical and sensory characteristics of Cameros cheese packaged under modified atmospheres. Food Microbiol 17:407-414

ISO/IDF International Organization for Standardization/International Dairy Federation (2008) Cheese- determination of fat content—Van Gulik method. ISO 3433:2008 (IDF 222:2008)

Mahe MF, Manfredi E, Ricordeau G, Piacere A, Grosclaude F (1994) Effects of the alpha-S1-casein polymorphism on goat dairy performances. A within-sire analysis of Alpine bucks. Genet Sel Evol 26: $151-157$

Mas M, Tabla R, Moriche J, Roa I, Gonzalez J, Rebollo JE, Caceres P (2002) Ibores goat's milk cheese: microbiological and physicochemical changes throughout ripening. Lait 82:579-587

Moreno-Rojas R, Sanchez-Segarra PJ, Camara-Martos F, Amaro-Lopez MA (2010) Multivariate analysis techniques as tools for categorization of Southern Spanish cheeses: nutritional composition and mineral content. Eur Food Res Technol 231:841-851 
Navarro L, Ruiz FA, Castel JM, Hevilla S, Jiménez M (2009) Patrimonio quesero andaluz. Quesos de Andalucía. Grupo de Desarrollo Rural Valle del Guadalhorce, Málaga

Peláez Puerto P, Fresno Baquero M, Rodríguez Rodríguez EM, Darías Martín J, Díaz Romero C (2004) Chemometric studies of fresh and semi-hard goats' cheeses produced in Tenerife (Canary Islands). Food Chem 88:361-366

Psoni L, Tzanetakis N, Litopoulou-Tzanetaki E (2006) Characteristics of Batzos cheese made from raw, pasteurized and/or pasteurized standardized goat milk and a native culture. Food Control 17:109-120

Raynal-Ljutovac K, Lagriffoul G, Paccard P, Guillet I, Chilliard Y (2008) Composition of goat and sheep milk products: an update. Small Rumin Res 79:57-72

Sanchez-Macias D, Fresno M, Moreno-Indias I, Castro N, Morales-delaNuez A, Alvarez S, Argueello A (2010) Physicochemical analysis of full-fat, reduced-fat, and low-fat artisan-style goat cheese. J Dairy Sci 93:3950-3956

Tejada L, Abellan A, Prados F, Cayuela JM (2008) Compositional characteristics of Murcia al Vino goat's cheese made with calf rennet and plant coagulant. Int J Dairy Technol 61:119-125

Tejada L, Fernandez-Salguero J (2003) Chemical and microbiological characteristics of ewe milk cheese (Los Pedroches) made with a powdered vegetable coagulant or calf rennet. Ital J Food Sci 15:125-131 